\title{
ANALISIS BEBAN KERJA FISIOLOGI DAN PSIKOLOGI KARYAWAN PEMBUATAN BAJU DI PT JABA GARMINDO MAJALENGKA
}

\author{
Lalan Ruslani dan Nurfajriah \\ Program Studi Teknik Industri, Fakultas Teknik \\ Universitas Pembangunan Nasional Veteran Jakarta \\ JI. RS Fatmawati ñ Pondok Labu Jakarta Selatan 12450, Indonesia, Telp : 021-7856971 \\ Email :lalanruslani40@yahoo.co.id
}

\begin{abstract}
This study was conducted to determine the physiological workload and psychological employee mental burden of making clothes at each work station. The study was conducted at six work stations that work station QC Jodoh, Linking, QC Lampu, Pantek, Sontek and Obras. Calculation of physiological workload carried using the NASA-TLX. Physiological workload calculation results showed that the highest energy consumption experienced by the operator at the work station sontek (85,8 Kcal /hour), while the lowest value contained in the work station QC Jodoh (54 Kcal/hour). This job classified into light workload due to smaller than 100-200 Kcal/hour (according to Decree No. 5 1of 1999). Measurement of psychological workload on each carrier based questionnaire NASA-TLX which has been filled by 18 operators, obtained a total rating of each indicator psychological workloads different. This shows that the difference in the psychological workload experienced by the operator on each indicator.
\end{abstract}

Keywords : pulse rate, energy consumption, NASA - TLX, work physiology, psychology of work.

\section{PENDAHULUAN}

\section{Latar Belakang}

Sebuah pabrik manufaktur selalu menginginkan target produksi yang direncanakan dapat terpenuhi dengan tepat. Akan tetapi karena berbagai faktor baik secara internal maupun secara eksternal dapat menghambat proses produksi itu sendiri sehingga pencapaian target produksi masih jauh dari harapan.Pemenuhan permintaan produk dari konsumen dan pasar menuntut perusahaan untuk bekerja secara efektif agar produksi dapat berjalan sesuai dengan target dengan kualitas produk yang sesuai dengan standar.

Secara umum yang dimaksudkerja fisik (physical) adalah kerja yang memerlukan energi fisik otot manusia sebagai sumber tenaganya. Kerja fisik sering kali juga disebut sebagai "Manual Operation" dimana performance kerja sepenuhnya akan tergantung manusia baik yang berfungsi sebagai sumber tenaga (power) ataupun pengendalian kerja (control). Kerja fisik seringkali pula dikonotasikan sebagai kerja berat ataupun kerja kasar maka dapat dirumuskan sebagai kegiatan yang memerlukan usaha fisik manusia yang kuat selama periode kerja berlangsung. Dalam hal kerja fisik ini, maka konsumsi energi (energy consumpetion) merupakan faktor utama dan tolak ukur yang dipakai sebagai penentuan berat atau ringannya kerja tersebut. Proses mekanisme kerja dalam berbagai kasus akan diaplikasikan sebagai jalan keluar untuk mengurangi beban kerja yang terlalu berat dan harus dipikul manusia. Dengan mekanisme peran manusia sebagai sumber energi kerja akan digantikan oleh mesin.Hal ini akanmemberikan kemampuan yang lebih besar lagi untuk penyelesaian aktivitas-aktivitas yang memerlukan energi fisik yang berat dan berlangsung dalam periode waktu lama. (Sutalaksana, Iftikar, dkk. 1979).

Faktor pemulihan energi sangat penting diperhatikan karena selama proses kerja terjadi kelelahan. Hal ini diakibatkan oleh kedua hal yaitu kelelahan fisiologi (fisik) dan kelelahan psikologi (mental).Yang dimaksud kelelahan fosiologi adalah kelelahan yang timbul karena adanya perubahan faal tubuh. Perubahan faal tubuh dari kondisi segar menjadi letih akan mempengaruhi keoptimalan kinerja pekerja. Pemulihan kondisi faal tubuh untuk kembali pada kondisi segar selama berakti- 
vitas merupakan hal penting yang perlu diperhatikan. Salah satu faktor yang dapat mempengaruhi pemulihan energi adalah istirahat.Pekerja yang bekerja dengan beban kerja berat tentunya membutuhkan periode dan frekuensi yang berbeda dengan pekerja yang bekerja dengan beban kerja ringan.

PT Jaba Garmindo merupakan perusahaan yang bergerak di bidang manufaktur.Produk yang dihasilkan PT Jaba Garmindo adalah baju. Proses pembuatan baju dimulai dari barang setengah jadi yang datang dari Tanggerang lalu di cek fisik sesuai atau tidak dengan dokumen yang berkaitan. Baju masuk ke QC Jodoh untuk di cek apakah bahan tersebut lengkap atau tidak. Sesudah di cek di QC Jodoh dan dipastikan bahan tersebut lengkap, berikutnya bahan tersebut masuk ke dalam proses linking agar menjadi satu buah baju yang utuh. Dan dari linking berikutnya masuk ke QC Lampu untuk di cek apakah ada bagian-bagian yang rusak atau tidak sesuai dengan pola, dan jika ditemukan adanya kerusakan bisa diperbaiki secara manual (rajut) atau langsung dikembalikan ke proses linking. Jika baju tersebut sudah lolos secara proses QC, maka baju tersebut masuk ke proses selanjutnya yaitu proses ke dua, yaitu pemasangan aksesoris seperti size, lebel, main label (merek), cara label, dan sleting atau kancing. Lalu masuk lagi ke QC untuk di cek apakah posisi pemasangan aksesoris sudah pas atau tidak.

Target penyelesaian baju PT Jaba Garmindo sebanyak 256 per hari per line pada setiap stasiun kerja. Target per operator per hari yaitu operator di tes dalam waktu 1 jam sehingga berapa banyak operator dapat menyelesaikan baju tersebut. Operator yang paling banyak menyelesaikan baju akan manjadi target banyaknya baju yang harus diselesaikan operator lain per stasiun kerja. Berikut tabel 1 data target per line per hari:

Tabel 1. Data Target Per Line Per Hari

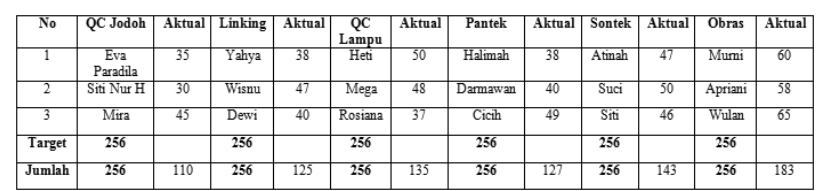

Berdasarkan wawancara diketahui masalah target tidak tercapai dikarenakan adanya beban kerja Fisiologi yaitu operator mudah cepat lelah dan Psikologi yaitu operator mudah cepat bosan, maka perlu dilakukan penelitian untuk menghitung beban kerja tersebut.

\section{Perumusan Masalah}

Karyawan yang mengalami kelelahan secara fisiologi (fisik) dan psikologi (mental) dapat menyebabkan penurunan pada produksi yang dihasilkan oleh perusahaan.Jika hal ini tidak diperhatikan bisa mengakibatkan masalah terhadap keberlangsungan karyawan dan perusahaan itu sendiri.

\section{Pembatasan Masalah}

Agar penelitian ini berfokus pada tujuan dan tidak menyimpang pada masalah yang telah dirumuskan maka perlu diberikan pembatasan masalah sebagai berikut:

1. Penelitian dilakukan pada proses pembuatan baju di PT Jaba Garmindo Majalengka, dan objek penelitian adalah operator di PT Jaba Garmindo Majalengka.

2. Penilaian fisiologi dilakukan dengan cara menghitung denyut nadi dimana denyut nadi diambil pada saat bekerja dan pada saat istirahat.

3. Penilaian psikologi menggunakan metode NASA TLX.

4. Data proses stasiun kerja QC Jodoh, stasiun kerja Linking, stasiun kerja QC Lampu, stasiun kerja Pantek, stasiun kerja Sontek dan stasiun kerja Obras.

5. Jumlah waktu keseluruhan untuk mengambil data fisiologi adalah 30 menit dikarenakan keterbatasan waktu penelitian/pengambilan data.

\section{Tujuan Dan Manfaat Penelitian Tujuan Penelitian}

Mengukur beban kerja secara fisiologi, psikologi dan analisis terhadap prosesproduksi perusahaan.

\section{Manfaat Penelitian}

Hasil penelitian ini diharapkan dapat memberikan manfaat bagi unsur-unsur terkait, dapat digunakan sebagai literatur dan alternatif perbaikan metode kerja dalam hal perbaikan kinerja dan pengamatan energi fisik operator pada saat bekerja dalam upaya memberikan perlindungan terhadap kesehatan operator dan peningkatan produktifitas kerja.

\section{Landasan Teori \\ Tujuan Ergonomi}

Secara umum tujuan dari penerapan 
ergonomi menurut Tarwaka (2004:7) adalah sebagai berikurt:

1. Meningkatkan kesejahteraan fisik dan mental melalui upaya pencegahancidera dan penyakit akibat kerja, menurunkan beban kerja fisik danmental, mengupayakan promosi dan kepuasan kerja.

2. Meningkatkan kesejahteraan sosial melalui peningkatan kualitas kontaksosial, mengelola dan mengkoordinir kerja secara tepat guna danmeningkatkan jaminan sosial baik selama kurun waktu usia produktifmaupun setelah tidak produktif.

3. Menciptakan keseimbangan rasional antara berbagai aspek yaitu aspek teknis, ekonomis, antropologis dan budaya dari setiap sistem kerja yang dilakukan sehingga tercipta kualitas hidup yang tinggi.

\section{Konsep Keseimbangan Dalam Ergonomi}

Ergonomi merupakan suatu ilmu, seni dan teknologi yang berupaya untuk menyerasikan alat, cara dan lingkungan kerja terhadap kemampuan,kebolehan dan segala keterbatasan manusia, sehingga manusia dapatberkarya secara optimal tanpa pengaruh buruk dari pekerjaannya. Dari sudutpandang ergonomi, antara tuntutan tugas dengan kapasitas kerja harus selaludalam garis keseimbangan sehingga dicapai performansi kerja yang tinggi.Dalam kata lain, tuntutan tugas tidak boleh terlalu rendah (underload) danjuga tidak boleh terlalu berlebihan (overload). Karena keduanya, baikunderload maupun overload akan menyebabkan stress.

Konsep keseimbangan antara kapasitas kerja dengan tuntutan tugas tersebut dapat diilustrasikan pada Gambar 1 berikut:

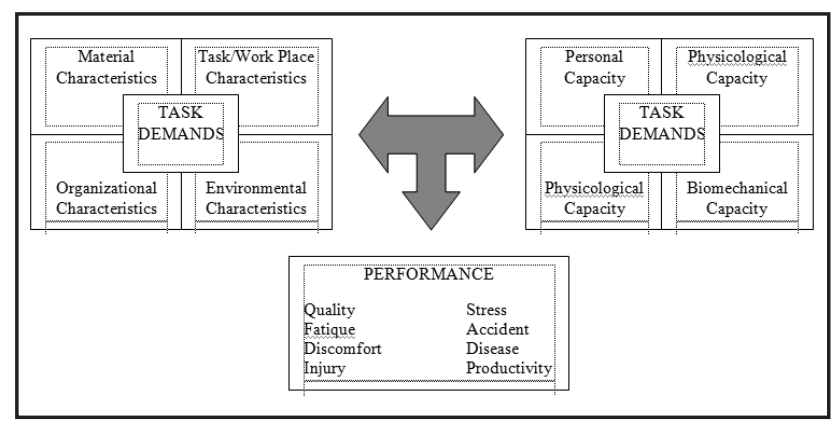

Sumber: Manuaba, 2000 dalam Tarwaka, dkk 2004

Gambar 1. Konsep Dasar Keseimbangan Dalam Ergonomi

1. Kemampuan Kerja (Work Capacity)

a. Personal Capacity (Karakteristik Pribadi); meliputi faktor usia, jenis kelamin, antropometri, pendidikan, pengalaman, status sosial, agama dan kepercayaan.

b. Physicological Capacity (Kemampuan Fisiologis); meliputi kemampuan dan daya tahan cardio-vaskuler, syaraf otot, panca indera.

c. Biomechanical Capacity (Kemampuan Biomekanik) berkaitandengan kemampuan dan daya tahan sendi dan persendian, tendondan jalinan tulang.

2. Tuntutan Tugas (Task Demand)

a. Task and Material Characteristic (Karakteristik tugas dan Material);ditentukan oleh karakteristik peralatan dan mesin, tipe, kecepatandan irama kerja.

b. Organization Characteristic; berhubungan dengan jam kerja danjam istirahat, shift kerja, cuti dan libur, manajemen.

c. Environmental Characteristic; berkaitan dengan teman setugas, kondisi lingkungan kerja fisik,norma, adat kebiasaan dan sosial budaya.

3. Performansi (Performance)

a. Bila rasio tuntutan tugas (Task Demand) > Kapasitas kerja (WorkCapacity), maka hasil akhirnya berupa: ketidaknyamanan overstress, kelelahan, kecelakaan, cidera, rasa sakit dan tidak produktif.

b. Bila rasio tuntutan tugas (Task Demand) < Kapasitas kerja (WorkCapacity), maka hasil akhirnya berupa: undertress, kebosanan, kejemuan, kelesuan, sakit dan tidakproduktif.

c. Agar penampilan menjadi optimal maka perlu adanya keseimbangandinamis (task demand $=$ Work capacity) sehingga tercapai kondisilingkungan yang sehat, aman, nyaman dan produktif.

Untuk mencapai tujuan ergonomi seperti yang telah dikemukakan, maka perlu keserasian antara pekerja dan pekerjaannya, sehingga pekerja dapat bekerja sesuai dengan kemampuan dan keterbatasannya.Secara umum kemampuan dan keterbatasan manusia ditentukan oleh berbagai faktor yaitu umur, jenis kelamin, ras, antropometri, status kesehatan, gizi, kesehatan jasmani, pendidikan, keterampilan, budaya, tingkah laku, kebiasaan dan kemampuan beradaptasi.

\section{Beban Kerja}

Tubuh manusia dirancang untuk dapat 
melakukan aktivitas pekerjaan sehari hari. Adanya massa otot yang bobotnya hampir lebih dari separuh beban tubuh, memungkinkan kita untuk dapat menggerakkan dan melakukan pekerjaan. Pekerjaan disatu pihak mempunyai arti penting bagi kemajuan dan peningkatan prestasi, sehingga mencapai kehidupan yang produktif sebagai satu tujuan hidup. Dipihak lain, bekerja berarti tubuh akan menerima beban dari luar tubuhnya. Dengan kata lain bahwa setiap pekerjaan merupakan beban bagi yang bersangkutan.Beban tersebut dapat berupa beban fisik maupun mental.

Dari sudut pandang ergonomi, setiap beban kerja yang diterima oleh seseorang harus sesuai atau seimbang baik dalam kemampuan fisik, maupun kognitif, maupun keterbatasan manusia yang menerima beban tersebut.Kemampuan kerja seorang tenaga kerja berbeda dari satu kepada yang lainnya dan sangat tergantung dari tingkat ketrampilan, kesegaran jasmani,usia dan ukuran tubuh dari pekerja yang bersangkutan.

\section{Faktor-faktor yang Mempengaruhi Beban Kerja}

Menurut Rodhal, Adiputra dan Manuaba dalamTarwaka (2004 : 95), bahwa secara umum hubungan antara beban kerjadan kapasitas kerja dipengaruhi oleh berbagai faktor yang sangat kompleks,baik faktor internal maupun faktor eksternal.

1. Beban Kerja Oleh Karena Faktor Eksternal Faktor eksternal beban kerja adalah beban kerja yang berasal dariluar tubuh pekerja, meliputi:

a. Tugas-tugas (task)

Meliputi tugas bersifat fisik seperti, stasiun kerja, tata ruang tempatkerja, kondisi lingkungan kerja, sikap kerja, cara angkut, beban yangdiangkat. Sedangkan tugas yang bersifat mental meliputi, tanggungjawab, kompleksitas pekerjaan, emosi pekerja dan sebagainya.

b. Organisasi Kerja

Organisasi kerja meliputi lamanya waku kerja, waktu istirahat, shiftkerja, sistem kerja dan sebagainya.

c. Lingkungan Kerja

Lingkungan kerja ini dapat memberikan beban tambahan yang meliputi, lingkungan kerja fisik, lingkungan kerja kimiawi, lingkungan kerja biologis dan lingkungan kerja psikologis.

2. Beban Kerja Oleh Karena Faktor Internal Faktor internal beban kerja adalah faktor yang berasal dari dalamtubuh akibat adanya reaksi dari beban kerja eksternal yang berpotensi sebagai stressor, meliputi:

a. Faktor somatis (jenis kelamin, umur, ukuran tubuh, status gizi,kondisi kesehatan, dan sebagainya)

b. Faktor psikis (motivasi, persepsi, kepercayaan, keinginan, kepuasan dan sebagainya).

\section{Penilaian Beban Kerja Fisik}

Menurut Astrand dan Rodhal dalam Tarwaka (2004) bahwapenilaian beban kerja dapat dilakukan dengan dua metode secara objektif,yaitu metode penilaian langsung dan metode penilaian tidak langsung.

1. Metode Penilaian Langsung

Metode pengukuran langsung yaitu dengan mengukur energi yangdikeluarkan (energy expenditure) melalui asupan oksigen selama bekerja.Semakin berat beban kerja akan semakin banyak energi yang diperlukanuntuk dikonsumsi. Meskipun metode pengukuran asupan oksigen lebih akurat, namun hanya dapat mengukur untuk waktu kerja yang singkat dandi perlukan peralatan yang mahal.

Berikut adalah kategori beban kerja yang didasarkan pada metabolisme, respirasi suhu tubuh dan denyut jantung menurut Christensen (1991) pada tabel 2.berikut:

Tabel 2. Kategori Beban Kerja Berdasarkan Metabolisme, Respirasi, Suhu Tubuh dan Denyut Jantung

\begin{tabular}{|l|c|c|c|c|}
\hline $\begin{array}{c}\text { Kategori } \\
\text { Beban Kerja }\end{array}$ & $\begin{array}{c}\text { Konsumsi } \\
\text { Oksigen } \\
(\mathbf{I} / \text { min) }\end{array}$ & $\begin{array}{c}\text { Ventilasi } \\
\text { Paru } \\
(\mathbf{I} / \mathbf{m i n})\end{array}$ & $\begin{array}{c}\text { Suhu } \\
\text { Rektal } \\
\left({ }^{\circ} \mathbf{C}\right)\end{array}$ & $\begin{array}{c}\text { Denyut } \\
\text { Jantung } \\
(\mathbf{d e n y u t / m i n})\end{array}$ \\
\hline Ringan & $0,5-1,0$ & $11-20$ & 37,5 & $75-100$ \\
\hline Sedang & $1,0-1,5$ & $20-30$ & $37,5-38,0$ & $100-125$ \\
\hline Berat & $1,5-2,0$ & $31-43$ & $38,0-38,5$ & $125-150$ \\
\hline Sangat Berat & $2,0-2,5$ & $43-56$ & $38,5-39,0$ & $150-175$ \\
\hline $\begin{array}{l}\text { Sangat Berat } \\
\text { Sekali }\end{array}$ & $2,5-4,0$ & $60-100$ & $>39$ & $>175$ \\
\hline
\end{tabular}

Sumber: Christensen (1991:169). Encyclopedia of Occupational Health and Safety

\section{Metode Penilaian Tidak Langsung}

Metode penilaian tidak langsung adalah dengan menghitung denyut nadi selama bekerja. Pengukuran denyut jantung selama bekerja merupakan suatu metode untuk menilai cardiovasculair strain dengan metode 10 denyut (Kilbon, 1992) dimana dengan metode ini dapat dihitung denyut nadi kerjasebagai berikut: Denyut Nadi $($ denyut $/$ menit $)=$ 
Penggunaan nadi kerja untuk menilai berat ringannya beban kerjamempunyai beberapa keuntungan, selain mudah, cepat dan murah juga tidak diperlukan peralatan yang mahal serta hasilnya pun cukup reliabel dan tidak menganggu ataupun menyakiti orang yang diperiksa.

Denyut nadi untuk mengestimasi indek beban kerja fisik terdiri dari beberapa jenis yaitu: a. Denyut Nadi Istirahat (DNI) adalah rerata denyut nadi sebelum pekerjaan dimulai

b. Denyut Nadi Kerja (DNK) adalah rerata denyut nadi selama bekerja

c. Nadi Kerja (NK) adalah selisih antara denyut nadi istirahat dengan denyut nadi kerja. Dalam penentuan konsumsi energi biasanya digunakan seuatu bentuk hubungan energi dengan kecepatan denyut yaitu sebuah persamaan regresi kuadratis sebagai berikut:

$\mathrm{E}=1,80411-0,0229038 x+4,71733 \mathrm{X}$

$10-4 x^{2}$

Dimana:

$\mathrm{E}=$ Energi $(\mathrm{Kkal} / \mathrm{menit})$

$\mathrm{x}=$ Kecepatan denyut jantung/nadi (denyut/menit)

Setelah melakukan perhitungan di atas, kita dapat menghitung konsumsi energi dengan menggunakan persamaan:

$\mathrm{K}=\mathrm{Et}-\mathrm{Ei}$

Dimana:

$\mathrm{K}=$ Konsumsi energi (Kkal/menit)

$\mathrm{Et}=$ Pengeluaran energi pada waktu kerja tertentu (Kkal/menit)

Ei = Pengeluaran energi pada waktu sebelum bekerja

Sebagai dasar rekomendasi dari KEPMENAKER No. 51 Tahun 1999 yang menetapkan kategori beban kerja menurut kebutuhan kalori sebagai berikut:

1) Beban Kerja Ringan: 100 - $200 \mathrm{Kkal} / \mathrm{jam}$

2) Beban Kerja Sedang: $>200$ - $350 \mathrm{Kkal} / \mathrm{jam}$

3) Beban Kerja Berat : > 350 - $500 \mathrm{Kkal} / \mathrm{jam}$

Peningkatan denyut nadi mempunyai peranan yang sangat penting didalam peningkatan cardia output dari istirahat sampai kerja maksimum. Peningkatan yang potensial dalam denyut nadi dari istirahat sampai kerja maksimum oleh Rodahl (1989) dalam Tarwaka, dkk (2004:101) didefinisikan sebagai Heart Rate Reverse (HR Reverse) yang diekspresikan dalam presentase yang dapat dihitung menggunakan rumus sebagai berikut.

$\% H R$ Reverse $=\frac{D N K-D N I}{D N \max } \times 100 \ldots \ldots . .$.

Denyut Nadi maksimum (DNmax) adalah (220-umur) untuk laki-laki dan (200-umur) untuk perempuan.

Lebih lanjut untuk menentukan klasifikasi beban kerja berdasarkan peningkatan denyut nadi kerja yang dibendingkan dengan denyut nadi maksimum karena beban kardiovaskuler (cardiovasculair load $=\%$ CVL) dapat dihitung dengan rumus sebagai berikut:

$$
\% C V L=\frac{100 x(D N K-D N I)}{D N \max -D N I} \times 100
$$

Dari hasil perhitungan \% CVL tersebut kemudian dibandingkan dengan klasifikasi yang telah ditetapkan sebagai berikut:

Tabel 3. Klasifikasi Berat Ringan Beban Kerja Berdasarkan \% CVL

\begin{tabular}{|ll|}
\hline$\%$ CVL & Klasisfikasi \% CVL \\
\hline$<30 \%$ & Tidak terjadi kelelahan \\
$30 \%-60 \%$ & Diperlukan perbaikan \\
$60 \%-80 \%$ & Kerja dalam waktu singkat \\
$80 \%-100 \%$ & Diperlukan tindakan segera \\
$>100 \%$ & Tidak diperbolehkan beraktivitas \\
\hline
\end{tabular}

Sumber: Sarwo Widodo (2008)

\section{Beban Kerja Mental}

Menurut Hancock, P. A. dan Meshkati, N (1988) dalam bukunya "Human Mental Workload", definisi beban kerja mental yakni "Mental workload is the operator's evaluation of the attentional load margin (between their motivated capacitiy and the current task demands) while achieving adequate task performance in a mission relevant context". "Beban kerja mental adalah evaluasi operator dari margin beban atten-tional (antara kapasitas termotivasi mereka dan tuntutan tugas saat ini) sementara mencapai kinerja tugas yang memadai dalam konteks misi yang relevan".

Seiring dengan berjalannya waktu, kemampuan seseorang dapat saja berubah sebagi akibat dari praktek terhadap pekerjaan (kemampuan meningkat), kelelahan yang ditimbulkan (kemampuan menurun), dan kebosanan terhadap pekerjaan dan kondisi (kemampuan menurun), kemampuan 
seseorang akan berbeda dengan orang lain karena perbedaan dukungan fisik dan mental, perbedaan latihan dan perbedaan pekerjaan. Hubungan antara beban kerja dengan kinerja dapat dilihat dalam bentuk kurva U terbalik. Kinerja manusia pada tingkat beban kerja rendah tidak juga baik, jika tidak banyak hal yang dapat dikerjakan maka orang tersebut akan mudah bosan dan cenderung kehilangan ketertarikan terhadap pekerjaan yang dilakukan. Dalam keadaan ini (Underload), galat akan muncul dalam bentuk kehilangan informasi sebagai akibat dari menurunnya konsentrasi.

\section{Bagan Metode Penelitian}

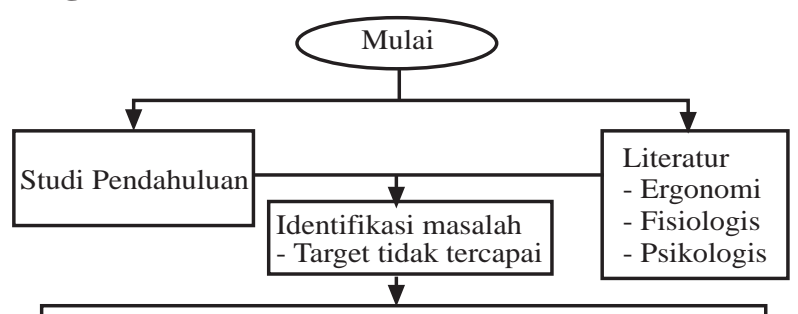

Tujuan Penelitian

- Menegetahui pengaruh beban kerja secara fisiologi dan psikkolog terhadap proses produksi perusahaan

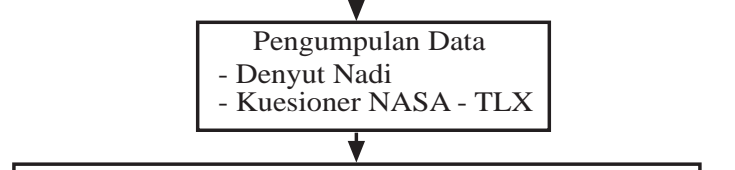

Pengolahan Data

Menghitung fisiologis dengan metode tidak langsung Menghitung 10 Denyut nadi

Menghitung beban mental kerja dengan metode NASA - TLX

\begin{tabular}{|c|}
\hline Analisis \\
- Analisis beban kerja fisiologis \\
- Analisis beban kerja psikologi \\
\hline Kesimpulan dan Saran \\
\hline
\end{tabular}

Sumber : Penelitian

Gambar 2. Flowchart Metode Penelitian

\section{Pengumpulan Data}

Adapun metode yang digunakan untuk mengumpulkan data dalam melakukan penelitian,yaitu: 1. Studi Lapangan (Observasi)

Metode pengumpulan data dengan mengadakan pengamatan langsung pada obyek yang diteliti. Observasi dilakukan guna mendapatkan data umum perusahaan yang meliputi kondisi umum perusahaan, aktivitas yang dilakukan pekerja di masing-masing stasiun kerja, dan jalannya proses produksi.

2. Wawancara (Interview)

Pengumpulan data dengan cara melakukan interview atau tanya jawab dengan narasumber yang terkait untuk penelitian yang dilakukan. Wawancara dilakukan pada pimpinan di bagian pembuatan baju dan sejumlah pekerja di bagian tersebut guna mendapatkan data yang benarbenar jelas.

Data yang diperoleh secara langsung dari tempat yang dijadikan sebagai obyek penelitian. Adapun data primer yang digunakan dalam penelitian ini meliputi data pengukuran metabolisme tubuh untuk menilai beban kerja dan pengukuran beban kerja mental dengan menggunakan metode Nation Aeronautics and Space Administration-Task Load Index (NASA-TLX).

Data yang diperoleh dari luar perusahaan yang ada hubungannya dengan obyek penelitian yang dilakukannya. Adapun data sekunder yang digunakan dalam penelitian ini diperoleh dari: 1. Studi Pustaka

Sumber data yang berasal dari buku-buku referensi yang relevan dan mendukung dengan obyek penelitian.

2. Media Internet

Sumber data yang berasal dari media internet yang berupa jurnal maupun artikel yang mendukung dengan obyek penelitian.

Dan adapun data Primer yang digunakan dalam penelitian ini diperoleh dari:

1. 10 denyut nadi pada karyawan/operator PT Jaba Garmindo kepada 18 operator dengan 6 stasiun kerja.

2. Kuesioner NASA-TLX.

\section{Pengumpulan Data 10 Denyut Nadi}

Pengumpulan data dilakukan dengan cara mengukur per-10 denyut nadi operator di setiap stasiun kerja pada PT Jaba Garmindo. Pengukuran dilakukan selama bekerja dan waktu istirahat. Berikut tabel data denyut nadi sesuai stasiun kerja masing-masing:

Tabel 4. Data Denyut Nadi Sesuai Stasiun Kerja (detik)

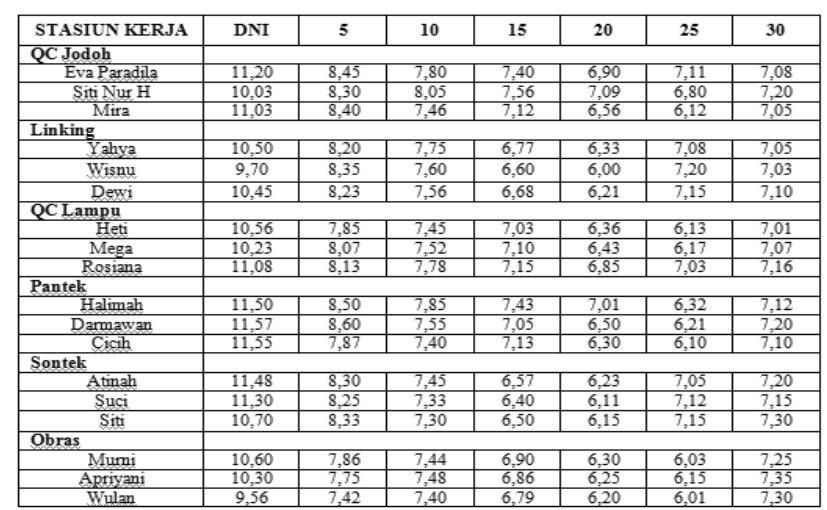




\section{PEMBAHASAN}

\section{Perhitungan Beban Kerja Fisiologis Dengan} Metode Tidak Langsung

Metode penilaian tidak langsung adalah dengan menghitung denyut nadi selama bekerja. Pengukuran denyut jantung selama bekerja merupakan suatu metode untuk menilai beban kerja dengan metode 10 denyut nadi dimana metode ini dapat dihitung sebagai berikut:

Denyut Nadi $($ denyut $/ \mathrm{m})=\frac{10 \text { denyut }}{\text { waktu perhitungan }} \times 60$

Contoh perhitungan denyut nadi istirahat dengan menggunakan metode 10 denyut, contoh untuk salah satu operator pada stasiun kerja QC Jodoh Eva Paradila:
DNI (detik)$$
=11,20
$$

Denyut Nadi $($ denyut $/ \mathrm{m})=\frac{10 \text { denyut }}{\text { waktu perhitungan }}$ X 60

$\mathrm{DNI}($ denyut $/ \mathrm{m})=\frac{10 \text { denyut }}{11,20} \times 60$

$$
=53,57 \text { denyut } / \text { menit }
$$

Perhitungan denyut nadi kerja dengan menggunakan metode 10 denyut, contoh untuk operator Eva Paradila:

$$
\operatorname{DNK}(\text { detik) } \quad=8,45
$$

Denyut Nadi $($ denyut $/ \mathrm{m})=\frac{10 \text { denyut }}{\text { waktu perhitungan }} \times 60$ DNK (denyut $/$ menit $)=\frac{10 \text { denyut }}{11,20} \times 60$

$=71,00 \mathrm{denyut} / \mathrm{men}$

Setelah dilakukan perhitungan maka diperoleh hasil rekapitulasi seperti pada tabel dibawah ini. Untuk lebih lengkapnya dapat dilihat pada tabel 5. berikut:

Tabel 5. Rekapitulasi Hasil Perhitungan Denyut Nadi pada

\begin{tabular}{|c|c|c|c|c|c|c|c|c|c|c|}
\hline \multirow[b]{2}{*}{ No } & \multirow[b]{2}{*}{ Nama } & \multirow{2}{*}{$\begin{array}{c}\text { Umur } \\
\text { (tahun) }\end{array}$} & \multirow{2}{*}{$\begin{array}{c}\text { DNI } \\
\text { (denyut) }\end{array}$} & \multicolumn{6}{|c|}{ DNK (denyut) } & \multirow{2}{*}{$\begin{array}{l}\text { Rata-Rata } \\
\text { (denyut) }\end{array}$} \\
\hline & & & & 5 & 10 & 15 & 20 & 25 & 30 & \\
\hline 1 & $\begin{array}{l}\text { Eva } \\
\text { Paradila }\end{array}$ & 25 & 53,57 & 71,00 & 76,92 & 81,08 & 86,96 & 84,39 & 84,75 & 80,85 \\
\hline 2 & Siti Nur H & 27 & 59,82 & 72,29 & 74,53 & 79,36 & 84,63 & 88,23 & 83,33 & 80,39 \\
\hline 3 & Mira & 23 & 54,40 & 71,43 & 80,43 & 84,27 & 91,46 & 98,04 & 85,11 & 85,12 \\
\hline
\end{tabular}
Stasiun Kerja QC Jodoh 10 Denyut

\section{Penilaian Konsumsi Energi}

Setelah melakukan perhitungan 10 denyut nadi, selanjutnya menghitung perhitungan konsumsi energi seperti dibawah ini:

1. Penilaian Konsumsi Energi Pada Stasiun Kerja QC Jodoh
Konsumsi Energi $(\mathrm{E})=$ $\left.\left(1,80411-0,0229038 X+4,71733 \times 10^{-4}(X)^{2}\right)\right) \times 60$

a. Eva Paradila

$$
\begin{aligned}
& \text { Et }=(1,80411-0,0229038(80,85)+4,717 \\
& \left.\left.33 \times 10^{-4}(80,85)^{2}\right)\right) \times 60 \\
& =(1,80411-1,85+4,71733 \times 0,63)) \times 60 \\
& =2,93 \times 60=176 \mathrm{Kkal} / \mathrm{jam} \\
& \text { Eva Paradila } \\
& \mathrm{Ei}=(1,80411-0,0229038(53,57)+4,717 \\
& \left.\left.33 \times 10^{-4}(53,57)^{2}\right)\right) \times 60 \\
& =(1,80411-1,23+4,71733 \times 0,29)) \times 60 \\
& =1,94 \times 60 \\
& =116 \mathrm{Kkal} / \mathrm{jam} \\
& \mathrm{K}=\mathrm{Et} \mathrm{Ei} \\
& =176 \mathrm{Kkal} / \mathrm{jam} 116 \mathrm{Kkal} / \mathrm{jam} \\
& =60 \mathrm{Kkal} / \mathrm{jam}
\end{aligned}
$$

Sehingga dari seluruh pengolahan data diatas dapat diperoleh hasil seperti pada Tabel 6 dibawah ini.

Tabel 6. Hasil Penilaian Konsumsi Energi Pada Stasiun Kerja QC Jodoh

\begin{tabular}{|c|c|c|}
\hline No & Keterangan & Hasil \\
\hline 1 & Eva Paradila Konsumsi Energi $(\mathrm{Kkal} / \mathrm{jam})$ & 60 \\
\hline 2 & Siti Nur H Konsumsi Energi $(\mathrm{Kkal} / \mathrm{jam})$ & 54 \\
\hline 3 & Mira Konsumsi Energi $(\mathrm{Kkal} / \mathrm{jam})$ & 79,2 \\
\hline
\end{tabular}

\section{Pengukuran Beban Kerja Psikologi}

Tabel 7 menunjukkan rekapitulasi skor indikator beban kerja psikologis untuk 18 operator seluruh stasiun kerja seperti dibawah ini:

Tabel 7. Rekapitulasi Pemberian Rating Pada Operator Seluruh Stasiun Kerja

\begin{tabular}{|c|c|c|c|c|c|c|c|}
\hline \multirow{2}{*}{ No } & \multirow{2}{*}{ Operator } & \multicolumn{7}{|c|}{ NASA TLX } \\
\cline { 3 - 8 } & & $\begin{array}{c}\text { Mental } \\
\text { Demand } \\
\text { (MD) }\end{array}$ & $\begin{array}{c}\text { Physical } \\
\text { Demand } \\
\text { (PD) }\end{array}$ & $\begin{array}{c}\text { Temporal } \\
\text { Demand } \\
\text { (TD) }\end{array}$ & $\begin{array}{c}\text { Performance } \\
\text { (OP) }\end{array}$ & $\begin{array}{c}\text { Frustation } \\
\text { Level (FR) }\end{array}$ & $\begin{array}{c}\text { Effort } \\
\text { (EF) }\end{array}$ \\
\hline $\mathbf{1}$ & Eva Paradila & 80 & 60 & 80 & 90 & 70 & 80 \\
\hline $\mathbf{2}$ & Siti Nur H & 90 & 80 & 90 & 80 & 70 & 90 \\
\hline $\mathbf{3}$ & Mira & 70 & 70 & 80 & 80 & 70 & 80 \\
\hline $\mathbf{4}$ & Yahya & 80 & 60 & 80 & 80 & 90 & 90 \\
\hline $\mathbf{5}$ & Wisnu & 80 & 80 & 70 & 70 & 60 & 70 \\
\hline $\mathbf{6}$ & Dewi & 70 & 60 & 80 & 90 & 70 & 60 \\
\hline $\mathbf{7}$ & Heti & 80 & 70 & 80 & 80 & 60 & 60 \\
\hline $\mathbf{8}$ & Mega & 90 & 70 & 80 & 70 & 70 & 80 \\
\hline $\mathbf{9}$ & Rosiana & 70 & 60 & 60 & 70 & 70 & 80 \\
\hline $\mathbf{1 0}$ & Halimah & 80 & 60 & 70 & 80 & 60 & 70 \\
\hline $\mathbf{1 1}$ & Darmawan & 60 & 70 & 70 & 60 & 70 & 80 \\
\hline $\mathbf{1 2}$ & Cicih & 70 & 60 & 70 & 80 & 70 & 70 \\
\hline $\mathbf{1 3}$ & Atinah & 70 & 80 & 70 & 70 & 70 & 80 \\
\hline $\mathbf{1 4}$ & Suci & 80 & 70 & 80 & 80 & 70 & 70 \\
\hline $\mathbf{1 5}$ & Siti & 80 & 80 & 80 & 70 & 60 & 70 \\
\hline $\mathbf{1 6}$ & Murni & 70 & 70 & 80 & 80 & 70 & 60 \\
\hline $\mathbf{1 7}$ & Apriyanti & 70 & 80 & 80 & 80 & 70 & 80 \\
\hline $\mathbf{1 8}$ & Wulan & 80 & 70 & 80 & 80 & 80 & 70 \\
\hline
\end{tabular}

Pada tabel 8 menunjukan rekapitulasi perbandingan berpasangan yang terdiri dari 15 perbandingan berpasangan untuk 18 operator hasil dari data pada tabel 8 Operator diminta untuk memilih salah satu dari dua indikator yang dirasakan lebih dominan menimbulkan beban kerja mental terhadap pekerjaan tersebut. 
Tabel 8. Rekapitulasi Perbandingan Berpasangan Pada Operator Seluruh Stasiun Kerja

\begin{tabular}{|c|c|c|c|c|c|c|c|}
\hline \multirow{2}{*}{ No } & \multirow{2}{*}{ Operator } & \multicolumn{7}{|c|}{ NASA TLX } \\
\cline { 3 - 8 } & $\begin{array}{c}\text { Mental } \\
\text { Demand } \\
\text { (MD) }\end{array}$ & $\begin{array}{c}\text { Physical } \\
\text { Demand } \\
\text { (PD) }\end{array}$ & $\begin{array}{c}\text { Temporal } \\
\text { Demand } \\
\text { (TD) }\end{array}$ & $\begin{array}{c}\text { Performance } \\
\text { (OP) }\end{array}$ & $\begin{array}{c}\text { Frustation } \\
\text { Level (FR) }\end{array}$ & $\begin{array}{c}\text { Effort } \\
\text { (EF) }\end{array}$ \\
\hline $\mathbf{1}$ & Eva Paradila & 2 & 1 & 4 & 3 & 1 & 4 \\
\hline $\mathbf{2}$ & Siti Nur H & 1 & 0 & 4 & 4 & 3 & 3 \\
\hline $\mathbf{3}$ & Mira & 1 & 3 & 3 & 3 & 0 & 5 \\
\hline $\mathbf{4}$ & Yahya & 2 & 0 & 3 & 2 & 4 & 4 \\
\hline $\mathbf{5}$ & Wisnu & 3 & 3 & 2 & 1 & 1 & 5 \\
\hline $\mathbf{6}$ & Dewi & 4 & 0 & 3 & 5 & 2 & 1 \\
\hline $\mathbf{7}$ & Heti & 4 & 3 & 3 & 3 & 0 & 2 \\
\hline $\mathbf{8}$ & Mega & 5 & 0 & 3 & 2 & 1 & 4 \\
\hline $\mathbf{9}$ & Rosiana & 4 & 2 & 0 & 3 & 2 & 4 \\
\hline $\mathbf{1 0}$ & Halimah & 4 & 1 & 3 & 5 & 0 & 2 \\
\hline $\mathbf{1 1}$ & Darmawan & 1 & 3 & 3 & 1 & 3 & 4 \\
\hline $\mathbf{1 2}$ & Cicih & 3 & 0 & 3 & 5 & 1 & 3 \\
\hline $\mathbf{1 3}$ & Atinah & 2 & 3 & 5 & 1 & 0 & 4 \\
\hline $\mathbf{1 4}$ & Suci & 4 & 1 & 4 & 4 & 0 & 2 \\
\hline $\mathbf{1 5}$ & Siti & 2 & 4 & 4 & 0 & 1 & 4 \\
\hline $\mathbf{1 6}$ & Murni & 1 & 2 & 3 & 5 & 0 & 4 \\
\hline $\mathbf{1 7}$ & Aprivani & 1 & 4 & 4 & 3 & 1 & 2 \\
\hline $\mathbf{1 8}$ & Wulan & 2 & 2 & 2 & 5 & 0 & 4 \\
\hline
\end{tabular}

Berdasarkan kuesioner ini dihitung jumlah tally dari setiap indikator yang dirasakan paling berpengaruh. Jumlah tally ini kemudian akan menjadi bobot untuk setiap indikator beban mental. Untuk mendapatkan skor beban mental NASATLX, bobot dan rating dikalikan kemudian dijumlahkan dan dibagi 15 (jumlah perbandingan berpasangan). Seperti tabel 25 dibawah ini:

Tabel 9. Perhitungan Bobot Setiap Indikator Untuk Operator QC Jodoh

\begin{tabular}{|l|l|l|r|}
\hline 1 & Mental Demand (MD) & $2 \times 80=$ & 160 \\
\hline 2 & Physical Demand (PD) & $1 \times 60=$ & 60 \\
\hline 3 & Temporal Demand (TD) & $4 \times 80=$ & 320 \\
\hline 4 & Performance (OP) & $3 \times 90=$ & 270 \\
\hline 5 & Frustation Level (FR) & $1 \times 70=$ & 70 \\
\hline 6 & Effort (EF) Jumlah & $4 \times 80=$ & 320 \\
\hline \multicolumn{3}{|c|}{ Jur } \\
\hline
\end{tabular}

Pengukuran beban kerja psikologis pada operator 1 stasiun kerja QC Jodoh berdasarkan kuesioner NASA-TLX yang telah diisi oleh operator, didapatkan total rating masing-masing indikator beban kerja psikologis yang berbeda-beda. Hal ini menunjukan bahwa adanya perbedaan beban kerja psikologis yang dialami operator pada masingmasing indikator. Berdasarkan nilai yang diberikan oleh masing-masing operator indikator Temporal Demand (TD) dan Effort (EF) mendapat nilai yang paling besar dan indikator Physical Demand (PD) mendapat nilai yang paling rendah. Hal ini menunjukan bahwa pada operator 1 stasiun kerja QC Jodoh hanya sedikit mengalami beban psikologi sehingga operator tidak memerlukan pekerjaan fisik yang lebih besar, karena pekerjaan ini lebih membutuhkan gabungan usaha mental, fisik dan jumlah tekanan yang dialami operator terkait dengan waktu yang dirasakan selama pekerjaan berlangsung.
Perhitungan bobot dari setiap indikator pada 18 operator. Bobot dan rating untuk setiap indikator dikalikan kemudian di jumlahkan.

Untuk mendapatkan skor beban mental NASA TLX, jumlah dari indikator dan bobot dibagi 15 (jumlah perbandingan berpasangan).

$$
\begin{aligned}
& \text { NASA TLX }=\frac{\text { rating } x \text { bobot }}{15} \\
& \begin{aligned}
\text { Eva Paradila: NASA TLX } & =\frac{1200}{15} \\
& =80
\end{aligned}
\end{aligned}
$$

Dari perhitungan setiap indikator didapatkan hasil rekapitulasi perhitungan seperti pada tabel 10 dibawah ini:

\begin{tabular}{|c|c|c|c|c|c|c|c|c|c|}
\hline \multirow[b]{2}{*}{ No } & \multirow[b]{2}{*}{ Operator } & \multicolumn{6}{|c|}{ NASA TLX } & \multirow[b]{2}{*}{ Jumlah } & \multirow[b]{2}{*}{$\begin{array}{c}\text { Total } \\
\text { Jumlah }\end{array}$} \\
\hline & & $\begin{array}{l}\text { Mental } \\
\text { Demand } \\
\text { (MD) }\end{array}$ & $\begin{array}{c}\text { Physical } \\
\text { Demand } \\
\text { (PD) }\end{array}$ & $\begin{array}{l}\text { Temporal } \\
\text { Demand } \\
\text { (ID) }\end{array}$ & $\begin{array}{c}\text { Performance } \\
\text { (OP) }\end{array}$ & $\begin{array}{l}\text { Frustation } \\
\text { Level (FR) }\end{array}$ & Effort (EF) & & \\
\hline 1 & Eva Paradila & 160 & 60 & 320 & 270 & 70 & 320 & 1200 & 80.00 \\
\hline 2 & Siti Nur H & 90 & 0 & 360 & 320 & 210 & 270 & 1250 & 83.33 \\
\hline 3 & Mira & 70 & 210 & 240 & 240 & 0 & 400 & 1160 & 77.33 \\
\hline 4 & Yahya & 160 & 0 & 240 & 160 & 360 & 360 & 1280 & 85.33 \\
\hline 5 & Wisnu & 240 & 240 & 140 & 70 & 60 & 350 & 1100 & 73.33 \\
\hline 6 & Dewi & 280 & 0 & 240 & 450 & 140 & 60 & 1170 & 78.00 \\
\hline 7 & Heti & 320 & 210 & 240 & 240 & 0 & 120 & 1130 & 75.33 \\
\hline 8 & Mega & 450 & 0 & 240 & 140 & 70 & 320 & 1220 & 81.33 \\
\hline 9 & Rosiana & 280 & 120 & 0 & 210 & 140 & 320 & 1070 & 71.33 \\
\hline 10 & Halimah & 320 & 60 & 210 & 400 & 0 & 140 & 1130 & 75.33 \\
\hline 11 & Darmawan & 60 & 210 & 210 & 60 & 210 & 320 & 1070 & 71.33 \\
\hline 12 & Cicih & 210 & 0 & 210 & 400 & 70 & 210 & 1100 & 73.33 \\
\hline 13 & Arinah & 140 & 240 & 350 & 70 & 0 & 320 & 1120 & 74.66 \\
\hline 14 & Suci & 320 & 70 & 320 & 320 & 0 & 140 & 1170 & 78.00 \\
\hline 15 & Siti & 160 & 320 & 320 & 0 & 60 & 280 & 1140 & 76.00 \\
\hline 16 & Munni & 70 & 140 & 240 & 400 & 0 & 240 & 1090 & 72.66 \\
\hline 17 & Aprivani & 70 & 320 & 320 & 240 & 70 & 160 & 1180 & 78.66 \\
\hline 18 & Wulan & 160 & 140 & 160 & 400 & 0 & 280 & 1140 & 76.00 \\
\hline
\end{tabular}

Tabel 10. Rekapitulasi Perhitungan Bobot dari Setiap Indikator Pada Operator Seluruh Stasiun Kerja

\section{Analisis \\ Analisis Pengukuran Beban Kerja Fisiologi Dengan Denyut Nadi}

Untuk melihat rata-rata pengukuran denyut nadi disetiap stasiun kerja berdasarkan hasil pengolahan data dapat dilihat pada tabel 11 dibawah ini:

Tabel 11. Rata-Rata Denyut Nadi Operator Disetiap Stasiun Kerja

\begin{tabular}{|c|c|c|c|c|}
\hline \multirow{2}{*}{ No } & \multirow{2}{*}{ Stasiun Kerja } & \multicolumn{3}{|c|}{ DNK (denyut/menit) } \\
\cline { 3 - 5 } & & $\mathbf{1}$ & $\mathbf{2}$ & $\mathbf{3}$ \\
\hline 1 & QC Jodoh & 80,85 & 80,39 & 85,12 \\
\hline 2 & Linking & 83,97 & 85,06 & 84,52 \\
\hline 3 & QC Lampu & 86,67 & 85,66 & 81,93 \\
\hline 4 & Pantek & 82,09 & 84,43 & 86,60 \\
\hline 5 & Sontek & 84,82 & 85,79 & 85,03 \\
\hline 6 & Obras & 86,91 & 86,71 & 88,18 \\
\hline
\end{tabular}

Pada tabel 11 terlihat bahwa operator di stasiun kerja obras memiliki nilai denyut nadi tertinggi (88,18denyut/menit), dikarenakan pada stasiun kerja ini aktivitas kerja dari operator adalah menjahit barang setengah jadi menjadi barang jadimembutuhkan tenaga lebih besar, sehingga 
para pekerja mudah lelah dan menyebabkan denyut nadi tinggi. Nilai terendah adalah pada stasiun kerja QC jodoh (80,39denyut/menit), dikarenakan pada stasiun kerja QC jodoh ini hanya memeriksa bahan hasil produksi rajut yang masih berupa panel sehingga menjadi bahan yang siap untuk masuk ke proses produksi yang hanya membutuhkan tenaga ringan, sehingga para pekerja tidak mudah lelah dan denyut nadi tidak terlalu tinggi. Pekerjaan ini tergolong kedalam pekerjaan ringan karena $>75$ dan <100 denyut jantung (denyut/menit) dilihat dari kategori beban kerja yang didasarkan pada metabolisme,respirasi suhu tubuh dan denyut jantung menurut (Christensen, 1991).

\section{Analisa Perhitungan Konsumsi Energi}

Untuk melihat perhitungan rata-rata konsumsi energi disetiap stasiun kerja dapat dilihat pada tabel 12 dibawah ini:

Tabel 12. Rata - Rata Konsumsi Energi Disetiap Stasiun Kerja

\begin{tabular}{|c|c|c|c|c|}
\hline \multirow{2}{*}{ No } & \multirow{2}{*}{ Stasiun Kerja } & \multicolumn{3}{|c|}{ Operator } \\
\cline { 3 - 5 } & & $\mathbf{1}$ & $\mathbf{2}$ & $\mathbf{3}$ \\
\hline 1 & QC Jodoh & 80,00 & 83,33 & 77,33 \\
\hline 2 & Linking & 85,33 & 73,33 & 78,00 \\
\hline 3 & QC Lampu & 75,33 & 81,33 & 71,33 \\
\hline 4 & Pantek & 75,33 & 71,33 & 73,33 \\
\hline 5 & Sontek & 74,66 & 78,00 & 76,00 \\
\hline 6 & Obras & 72,66 & 78,88 & 76,00 \\
\hline \multicolumn{5}{|c}{}
\end{tabular}

Tabel 12 menunjukan perbandingan rata rata konsumsi energi setiap stasiun kerja. Konsumsi energi terbesar dialami oleh operator pada stasiun kerja sontek $(85,8 \mathrm{Kkal} / \mathrm{jam})$. Berdasarkan penjelasan yang telah diuraikan diatas, pada stasiun kerja sontek aktivitas kerja operator adalah menyembunyikan benang sisa linking yang masih panjang dengan cara di selipkan di antara sela sela jahitan. Sedangkan nilai yang paling rendah terdapat di stasiun kerja QC jodoh (54Kkal/jam) pekerjaan ini tergolong kedalam beban kerja ringan dikarenakan lebih kecil dari 100-200Kkal/jam (sesuai dengan kepmenaker No. 51 Tahun 1999).

\section{Analisis Beban Kerja Psikologi}

Berdasarkan penjelasan Hart dan Staveland (1981) dalam teori NASA-TLX, skor beban kerja yang diperoleh terbagi dalam tiga bagian yaitu pekerjaan menurut para responden tergolong berat jika >80, nilai 5080 menyatakan beban pekerjaan sedang, sedangkan nilai <50 menyatakan beban pekerjaan ringan. Output yang dihasilkan dari pengukuran dengan NASA-TLX ini berupa tingkat beban kerja mental yang dialami oleh pekerja dengan data tabel 13 sebagai berikut:

Tabel 13. Perbandingan Nilai NASA-TLX

\begin{tabular}{|c|c|c|c|c|}
\hline \multirow{2}{*}{ No } & \multirow{2}{*}{ Stasiun Kerja } & \multicolumn{3}{|c|}{$\begin{array}{c}\text { Konsumsi Energi } \\
\text { (Kkal/jam) }\end{array}$} \\
\cline { 3 - 5 } & & $\mathbf{1}$ & $\mathbf{2}$ & $\mathbf{3}$ \\
\hline 1 & QC Jodoh & 60,0 & 54,0 & 79,2 \\
\hline 2 & Linking & 68,4 & 64,2 & 70,2 \\
\hline 3 & QC Lampu & 81,0 & 73,2 & 69,0 \\
\hline 4 & Pantek & 71,4 & 82,2 & 85,2 \\
\hline 5 & Sontek & 82,8 & 85,8 & 75,6 \\
\hline 6 & Obras & 80,4 & 76,8 & 75,6 \\
\hline
\end{tabular}

Pada tabel 13 terlihat bahwa operator distasiun kerja linking memiliki skor NASA-TLX tertinggi $(85,33)$. Pada stasiun kerja ini aktivitas kerja dari operator harus extra sabar karena dalam menggabungkan panel-panel hasil rajut harus lebih teliti agar tidak ada produk (baju) yang cacat dan menyebabkan output tidak tercapai. Berdasarkan literatur pekerjaan di stasiun ini tergolong berat karena $>80$. Skor terendah adalah pada stasiun kerja QC lampu dan pantek adalah $(71,33)$ pekerjaan ini tergolong pekerjaan sedang karena skornya diatas 50 dan di bawah 80. Pada stasiun kerja QC lampu dan pantek, proses kerja yang dilakukan oleh operator stasiun kerja QC lampu hanya memeriksa bagian badan dan tangan, dan operator stasiun kerja pantek hanya menyembunyikan atau mematikan benang sisa proses linking agar tidak mudah jebol.

\section{KESIMPULAN \\ Beban kerja fisiologi}

Denyut nadi kerja tertinggi yang pernah dicapai pada stasiun kerja obras dengan denyut nadi rata-rata 88,18 (denyut/menit). Hal ini dapat menyebabkan para pekerja mudah lelah karena aktivitas kerja dari operator adalah menjahit barang setengah jadi menjadi barang jadi yang memerlukan tenaga lebih besar sehingga operator tersebut cepat lelah dan target tidak tercapai. Nilai denyut nadi kerja terendah terdapat pada stasiun kerja QC jodoh dengan denyut nadi rata-rata 80,39 (denyut/ menit). Hal ini dikarenakan proses kerja yang hanya memeriksa bahan hasil produksi rajut yang masih berupa panel menjadi bahan yang siap untuk masuk ke proses produksi sehingga operator tidak mudah lelah dalam melakukan pekerjaan ini.

Konsumsi energi terbesar dialami oleh operator pada stasiun kerja sontek rata-rata $(85,8 \mathrm{Kkal} /$ jam) beban kerja yang dialami oleh operator cukup 
berat, maka akan semakin pendek waktu untuk operator bekerja tanpa kelelahan dan gangguan fisiologis yang menyebab salah satu faktor target tidak tercapai.

\section{Beban kerja psikologi}

Skor NASA-TLX tertinggi terdapat pada stasiun kerja linking dengan rata-rata $(85,33)$. Pada stasiun kerja ini aktivitas kerja dari operator harus extra sabar karena dalam menggabungkan panelpanel hasil rajut harus lebih teliti agar tidak ada produk (baju) yang cacat dan menyebabkan target tidak tercapai.

\section{DAFTAR PUSTAKA}

Achmad Zulfitroh, Tengku. 2014. Analisis Beban Kerja Fisiologis Dan Psikologis Pada Pembuatan Karton Box Kecil Di PT. Cahaya Mandala.

Hancock, P. A. dan Meshkati, N. 1988. Human Mental Workload. Elsevier.

Hart, S.G. 2006. NASA-Task Load Index (NASATLX), 20 Years Later. In Human Factors and Ergonomics Society 50th Annual Meeting (pp. 904-908). Santa Monica. CA: Human Factors and Ergonomics Society. Nurmianto, Eko. 1996. Ergonomi: Konsep Dasar dan Aplikasinya. Surabaya: GunaWidya.

Sutalaksana, Iftikar, dkk. 1979. Teknik Tata Cara Kerja. Bandung: Departemen Teknik Industri-ITB Bandung.

Tarwaka, dkk. 2004. Tujuan Ergonomi. Surakarta: UNIBA Press.

Widodo, Sarwo. 2008. Penentuan Lama Waktu Istirahat Berdasarkan Beban Kerja Dengan Menggunakan Pendekatan Fisiologis.

http://eprints.ums.ac.id/1666/1/D6000200 64.pdf 